\title{
Psicomotricidade e desenvolvimento: concepções e vivências de professores da educação infantil na amazônia setentrional
}

\section{Psicomotricity and development: conceptions and experiences of pre-school teachers in the northern amazon}

Psicomotricidad y desarrollo: concepciones y vivencias de profesores de la educación infantil en la amazonia sientrional

\section{I donézia Collodel Benetti*}

Universidade Federal de Santa Catarina - UFSC, Santa Catarina, Florianópolis, Brasil

\author{
Paulo Henrique Pinheiro de Barros** \\ Universidade Federal de Roraima - UFRR, Boa Vista, Roraima, Brasil
}

Fernanda Ax Wilhelm***

Universidade Federal de Roraima - UFRR, Boa Vista, Roraima, Brasil

\section{Ana Paula da Rosa Deon****}

Universidade Federal de Roraima - UFRR, Boa Vista, Roraima, Brasil

\section{J oão Paulo Roberti J unior*****}

Universidade Federal de Santa Catarina - UFSC, Santa Catarina, Florianópolis, Brasil

\begin{abstract}
RESUMO
A psicomotricidade está presente em todas as etapas da vida, porém o período da infância ganha destaque, uma vez que é nesta época em que as funções psicomotoras começam a se desenvolver. O objetivo desta pesquisa, de cunho exploratório, descritivo e de abordagem qualitativa, foi verificar qual a percepção de oito professoras pré-escolares sobre psicomotricidade e educação infantil. Para tanto foi utilizado um roteiro de entrevista semiestruturada, cujos resultados foram analisados sob a óptica temático-categorial da Análise de Conteúdo de Bardin. As categorias definidas foram: percepção das professoras sobre a relação entre psicomotricidade e educação infantil, atividades psicomotoras trabalhadas e aspectos que dificultam/facilitam o trabalho na área. Os resultados apontam que as professoras consideram que existe uma forte relação entre psicomotricidade e educação infantil. Quanto às atividades psicomotoras desenvolvidas, foi possível constatar que elas tiveram dificuldades para conceituar certas funções psicomotoras, principalmente em relação à orientação espacial. Quanto aos aspectos facilitadores e dificultadores, foi possível perceber que algumas apresentaram melhor condição para desenvolver atividades psicomotoras e outras afirmaram contar com a criatividade para lidar com a falta de materiais.
\end{abstract}


Palavras-chave: psicomotricidade, desenvolvimento, professoras, educação infantil.

\begin{abstract}
Psychomotricity is present in all stages of life, but it is highlighted during childhood, since it is at this time when the psychomotor functions begin to develop. This research, exploratory, descriptive and qualitative in nature, aims at verifying the perception of eight preschool teachers on psychomotricity and early childhood education. For this purpose, a semi-structured interview script was used, whose results were analyzed under the thematic-categorical optics of Bardin Content Analysis. The categories defined were: teachers' perceptions about the relationship between motor skills and early childhood education, psychomotor activities worked on and aspects/facilitators work in the area. As for the psychomotor activities developed, it was possible to verify that the teachers had difficulties to conceptualize certain psychomotor functions, mainly in relation to the spatial orientation. With regard to the facilitating and hindering aspects, it was possible to perceive that some teachers have a better condition to develop psychomotor activities and others stated that they rely on the creativity to deal with the lack of materials.
\end{abstract}

Keywords: psychomotricity, development, teachers, pre-school education.

\begin{abstract}
RESUMEN
La psicomotricidad está presente en todas las etapas de la vida, pero se destaca durante la infancia, ya que es en este momento cuando las funciones psicomotoras comienzan a desarrollarse. El objetivo de esta investigación, de cuño exploratorio, descriptivo y de abordaje cualitativo, fue verificar cuál es la percepción de ocho profesoras preescolares sobre Psicomotricidad y Educación Infantil. Con esta finalidad, se utilizó un guión de entrevista semi-estructurada, cuyos resultados fueron analizados bajo la óptica temático-categorial del Análisis de Contenido de Bardin. Las categorías definidas fueron: percepciones de los docentes sobre la relación entre psicomotricidad y educación de la primera infancia, actividades psicomotoras trabajadas y aspectos que dificultan y facilitan el trabajo en esta área. Los resultados apuntan que las profesoras consideran que existe una fuerte relación entre las habilidades motoras y la educación infantil. En cuanto a las actividades psicomotoras desarrolladas, fue posible constatar que ellas tuvieron dificultades para conceptualizar ciertas funciones psicomotoras, principalmente en relación a la orientación espacial. Con respecto a los aspectos facilitadores y dificultadores, fue posible percibir que algunas profesoras presentan mejor condición para desarrollar actividades psicomotoras y otras afirmaron contar con la creatividad para lidiar con la falta de materiales.
\end{abstract}

Palabras clave: psicomotricidad, desarrollo, maestros de educación de la primera infancia.

\title{
1 CONSI DERAÇÕES I NI CIAIS
}

A psicomotricidade promove ações terapêuticas e educativas e tem papel importante no desenvolvimento neuropsicológico das crianças. A idade "dourada" da psicomotricidade está situada desde o nascimento até os oito ou nove anos de idade, constituindo-se em uma necessidade no processo educativo desta fase da vida, já que busca a integração de interações cognitivas, emocionais, afetivas, simbólicas e físicas na 
capacidade do indivíduo de ser e atuar em um contexto psicossocial (Macri, 2014; Pieg, \& Vayer, 1971).

O termo Psicomotricidade é definido como sendo qualquer ação motriz, atitude ou padrão de comportamento que, sob a influência de processos mentais, integra e combina estes processos a aspectos motriculares, como elementos que influenciam o comportamento (Wauters-Krings, 2009). A Psicomotricidade, como parte da psicologia aplicada, aborda o estudo da função motriz, integrada e coordenada por funções mentais e tem sido associada à ideia de que dominar o corpo é a primeira condição para dominar o comportamento (Fonseca, 2012).

Entende-se por educação psicomotora "a educação da criança através de seu próprio corpo e de seu movimento, levando em consideração a idade, a cultura corporal, a maturação e os interesses da criança (Barreto, 2000, p. 29)". Esta educação atua de maneira preventiva para evitar má concentração, confusão de letras e de sílabas, confusão no reconhecimento de palavras nos momentos de leitura e escrita, permitindo que a criança tenha um bom desenvolvimento de suas faculdades intelectuais (Fonseca, 2005).

É, portanto, uma função complexa, envolvendo habilidade e comportamento específico, que integra e combina aspectos motriculares e psicológicos relacionados a funções perceptivas, desenvolvimento sensorial, intelectual e motor de recebimento de informações e execução adequada do ato de resposta. Então, a Psicomotricidade, como a própria palavra inscreve, atrela atividade motora a aspectos afetivos, cognitivos e sociais (Barreto, 2000).

A Educação Infantil é fundamental para o desenvolvimento motor das crianças, já que a permanência delas em um ambiente encorajador e sua participação em atividades motoras facilita um bom desenvolvimento e oferta possibilidades para maior potencial de exploração e interação (Kambas, Fatouros, Christoforidis, Venetsanou, Papageorgiou, \& Aggeloussis, 2010). Assim, a escola é o cenário ideal para melhorar as habilidades motoras da criança visando à otimização do desenvolvimento humano. Infelizmente, muitas escolas de Educação Infantil são caracterizadas por áreas de lazer limitadas, construções estreitas e grande número de alunos sob a tutela de um só professor, responsável pela educação sistematizada na primeira infância.

Importantes capacidades e conhecimentos sociais e emocionais podem ser aprendidos/ensinados em ambiente escolar, e a escola pode seguir programas de aprendizagem para desenvolver essas habilidades ao longo da vida. Os resultados positivos desses programas são a saúde do corpo, cidadãos mais responsáveis, menos relacionamentos mal sucedidos, menos violência interpessoal, abuso de drogas e infelicidade (Magill, 2011). Tudo isso vai ajudar a ter melhor qualidade de vida, saúde e realização pessoal e profissional (Sugrañés, \& Ángel, 2007). 
Dada a importância de atividades relacionadas à Psicomotricidade nesta fase da vida, a presente pesquisa teve como objetivos investigar a concepção de professoras sobre a relação entre Psicomotricidade e Educação Infantil e como estas profissionais vivenciam a Psicomotricidade em seu cotidiano de sala de aula. Saber o que os docentes pensam sobre estes temas pode auxiliar no desenho de projetos e programas de intervenção com o objetivo de maximizar possíveis mecanismos de proteção e diminuir os fatores de risco, no que se refere às possibilidades de uma resposta positiva da criança em face de adversidades diárias, que podem interferir na autoestima e imagem corporal, e podem resultar, mais tarde, em fracasso escolar e desempenho inadequado na sociabilidade. Diante do exposto, a possibilidade de averiguar concepções sobre a Psicomotricidade acena como um recurso de apoio a professores e crianças, com vistas à promoção de desenvolvimento humano saudável e nisto reside a relevância deste trabalho.

\section{PROCEDI MENTOS METODOLÓGI COS}

Esta investigação, de caráter exploratório e descritivo, de cunho transversal, com abordagem de análise qualitativa, ancorou-se nas técnicas propostas por Bardin (2010) para análise de conteúdo temático-categorial. Esta autora organiza em três momentos a técnica de análise de conteúdo: 1) pré-análise; 2) exploração do material e 3) inferência e tratamento dos resultados. Para a coleta de dados para análise, um roteiro para entrevista semiestruturada foi utilizado e, observados os parâmetros éticos - aprovação do Comitê de Ética da Universidade Federal de Roraima sob o parecer número 482.653 e assinatura do Termo de Consentimento Livre e Esclarecido (TCLE) -, foram entrevistados oito professores, que atuam junto às crianças de quatro e cinco anos de idade matriculadas em uma escola de Educação Infantil da Amazônia Setentrional.

Foi utilizado o critério de conveniência, sendo entrevistadas somente as professoras que estivessem dispostas a participar da pesquisa. Ainda, foram estabelecidos os seguintes critérios de inclusão: os participantes deveriam ser professores titulares da Rede Pública Municipal, com graduação em pedagogia. Neste estudo todos os participantes eram do sexo feminino e apresentaram média de idade de 30 anos. Todas as entrevistas foram realizadas individualmente e foram feitas através de visitas as escolas, após os participantes assinarem o Termo de Consentimento Livre e Esclarecido (TCLE). Para manter o anonimato as professoras-participantes são aqui denominadas como P1, P2, P3... P8. A partir dos domínios possíveis da aplicação da análise de conteúdo da vertente bardaniana, as entrevistas foram gravadas, transcritas e analisadas posteriormente. Entretanto, foi realizado um teste piloto 
para verificar se as questões elaboradas para o instrumento de coleta de dados estavam claras e, também, para treinar o entrevistador. Tendo por base que uma categoria se forma a partir do momento em que as palavras aparecem mais frequentemente citadas no material coletado (Silverman, 2014), as categorias encontradas foram: Percepção sobre a relação entre Psicomotricidade e Educação Infantil, Atividades psicomotoras trabalhadas e Aspectos dificultadores/facilitadores de se trabalhar com Psicomotricidade. A segunda categoria, referente às atividades psicomotoras trabalhadas, gerou sete subcategorias: Lateralidade, Esquema corporal, Orientação espacial, Orientação temporal, Coordenação motora ampla, Coordenação motora fina e Equilíbrio.

\section{ANÁLI SE E DISCUSSÃO DAS CONCEPÇÕES DAS PROFESSORAS}

\subsection{Psicomotricidade}

Nesta categoria, procurou-se investigar a percepção das professoras, sobre Psicomotricidade e P8 foi quem ofereceu uma definição que mais se aproxima da complexidade deste conceito, englobando 0 movimento, o intelecto e o afeto "Pra mim é movimento, você vai se movimentar, vai raciocinar, a partir do seu movimento, você já vai fazendo várias ações com o seu corpo" (P8); outra professora fez uma ligação entre movimento e raciocínio: "A psicomotricidade é uma relação entre o movimento, o intelecto e o afeto, sócioafetivo, para mim envolve esses três aspectos, e dentro dessa temática aí, a gente tem alguns elementos, como ritmo, lateralidade, espaço corporal, imagem corporal, e vários outros que [...]" (P6).

Observou-se que, nestas respostas, aparece a conceituação de Psicomotricidade e nomeação de algumas funções psicomotoras básicas, como o ritmo, imagem corporal, lateralidade, entre outros. Estas duas professoras compreendem a Psicomotricidade como uma ação que não separa corpo e mente, movimento e vida mental. Essas respostas mostram o que a literatura preconiza sobre este assunto: que os movimentos possuem uma parcela de sentimento (Fonseca, 2005). A professora P8 fornece uma interessante resposta ao afirmar que "[... ] psicomotricidade é movimento, e que a partir deste irá ocorrer o raciocínio". Não é possível, porém, afirmar a qual fase do desenvolvimento humano esta professora estava se referindo, porém o conceito trazido por ela remete à teoria que afirma que os movimentos realizados pelo bebê, nos primeiros meses de vida, são desprovidos de afeto, mas que, no entanto, são estes movimentos que irão permitir que o lado mental da criança desperte, começando uma verdadeira e intensa ligação entre movimento e afeto (Wallon, 2007). 
O conceito de Psicomotricidade também foi relacionado com escrita e equilíbrio: "No meu entender a psicomotricidade trabalha com a questão da... é como a criança vai começar a escrever, vai desenvolver, trabalhar o equilíbrio também" (P1). Ao falar motricidade, P4 ignorou o prefixo "psico", considerando apenas a dimensão física, relacionando-a também com a escrita e com a lateralidade: "A meu ver, é a maneira como trabalhar com a criança, a motricidade de lateralidade, de desenvolver essa parte de habilidades, da motricidade fina e grossa, trabalhar com objetos, o lápis e a caneta, adquirir habilidades de escrita".

É possível observar que o conceito de Psicomotricidade encontra-se um tanto limitado, ficando claro que os aspectos psicológicos não são percebidos como unidos ao movimento, indo na contramão dos conceitos desenvolvidos por vários autores, que estudam este assunto (Alves, 2008; Barreto, 2000; Fonseca, 2005; Le Boulch, 1982). Neste sentido, P5 conceituou a Psicomotricidade apenas como uma dimensão do movimento, mas deixou de lado as questões afetivas: "Pra mim tá relacionado com o movimento, com a expressão corporal e isso é a educação infantil, porque a criança tá sempre se movimentando, e é através do corpo que elas aprendem". P3 e P7 afirmaram não saber conceituar, enquanto P2 informa que sabe desenvolver a psicomotricidade junto às crianças, porém não sabe definir seu conceito.

É importante pontuar que em muitas escolas de Educação I nfantil não há uma prática que priorize o desenvolvimento psicomotor e, também, há lacunas abissais na construção de conhecimentos de Psicomotricidade, o que favorece o despreparo dos professores, tornando o conhecimento sobre o assunto limitado ou equivocado (Araújo, 2012). Há queixas oriundas de futuras pedagogas e de profissionais já atuantes no magistério sobre as falhas no seu processo de formação, que faz com que se sintam inseguros e, às vezes, momentaneamente incapazes para perceber a complexidade e a abrangência da Psicomotricidade, tanto no aspecto conceitual quanto funcional (Sayão, 2002).

\subsection{Atividades psicomotoras desenvolvidas pelas professoras}

Nesta categoria foram elaboradas perguntas relacionadas a algumas funções psicomotoras básicas, com 0 intuito de verificar se as professoras desenvolvem atividades ligadas a estas áreas, e de que maneiras elas são realizadas na prática. Também possibilitou verificar se há algum conhecimento por parte das professoras sobre tais funções. 


\subsubsection{Lateralidade}

Embora seja de difícil definição, a lateralidade deve ser compreendida como a dominância em relação ao eixo corporal - o domínio de um lado do corpo sobre o outro, ou seja, a prevalências motoras de um lado do corpo: do olho direito ou esquerdo, ouvido direito ou ouvido esquerdo, mão direita ou esquerda, pé direito ou esquerdo, e é um assunto muito importante na formação dos profissionais da educação (Barreto, 2000). Quanto às questões espaciais de esquerda e direita, nenhuma das profissionais ressaltou a questão da dominância lateral: "Eu acredito que a música trabalha muito isso... coloco aquelas músicas "de um lado para o outro" e assim, elas amam, e tem a brincadeira do vivo e morto que eu brinco de outra forma né "deita, rola, vira pro lado [...]" (P6). Para P4, este assunto é trabalhado através da música "Vou citar uma aqui que elas gostam muito "[...] levanta a mão direita, levanta a mão esquerda... levanta o pé esquerdo, abaixa o pé direito". O mesmo acontece com P8 que afirma que usa a música "[...] pra fazer esse tipo de trabalho. Por exemplo, cantando as músicas que têm gestos, que têm comandos".

Esses discursos demonstram que o entendimento de lateralidade se dá na esfera do movimento no espaço. Porém, outro ponto interessante, é que estas três professoras (P6, P4 e P8) destacam o uso da música como meio para trabalhar tais atividades - a música aparece atrelada ao movimento, dança e mímica. Observa-se que as técnicas utilizadas, na busca do desenvolvimento da psicomotricidade/lateralidade, são variadas, envolvendo brincadeiras com bola, música, amarelinha. Para desenvolver orientação e estrutura espacial, são utilizadas distinções entre esquerda/direita, de cima/baixo, frente/trás.

Percebe-se, ainda, que há uma prevalência em relação ao entendimento de lateralidade como estando relacionada à aprendizagem espacial de esquerda e direita, sendo utilizadas, para este fim, diversas brincadeiras (Tabela 1 ). Algumas professoras citam outras dimensões espaciais como "em cima e embaixo". Ou seja, estas noções de lateralidade, acabam divergindo da teoria, que preconiza que a lateralidade é compreendida como a dominância corporal em quatro níveis, ouvidos, olhos, mãos e pés (Sugrañés \& Ángel, 2007). 
Tabela1 - Transcrição de outras participantes sobre trabalho com lateralidade

\begin{tabular}{|l|l|}
\hline P3 & $\begin{array}{l}\text { Sim. Por exemplo, esquerda, direita, né? Entre outras. A gente vai brincar, pega uma bola... a } \\
\text { gente coloca uma determinada cor, na esquerda e na direita. Dai a criança vai ter que pular, } \\
\text { vamos lá criança, esquerda ou direita? }\end{array}$ \\
\hline P5 & Desenvolvo, trabalhar esquerda e direita, por meio de brincadeiras. \\
\hline P1 & $\begin{array}{l}E \text { E... esquerda e direta, eu trabalho também, hoje mesmo teve uma atividade que fala da } \\
\text { amarelinha, aquelas brincadeiras infantis... }\end{array}$ \\
\hline P7 & $\begin{array}{l}\text { Eu observo bastante nas aulas de educação fisica exatamente isso, a questão de em cima e } \\
\text { embaixo, direita e esquerda... passar a bolinha só pelo lado esquerdo, só pelo lado direito, por } \\
\text { cima e por baixo... }\end{array}$ \\
\hline
\end{tabular}

Aqui aparece o aspecto da fragilidade na formação profissional, já mencionado anteriormente. Porém, apesar da profundidade do conhecimento científico sobre o assunto deixar a desejar, o espaço para a brincadeira foi garantido. $E$, enquanto brinca, a criança expressa seus sentimentos, suas emoções, suas interações, aprimorando sua capacidade de memória e raciocínio, de forma alegre e agradável. Então, tendo em vista a importância do brincar para a formação integral da criança, é importante que haja formação continuada e apoio pedagógico, que consiga superar as fragilidades deixadas pela formação acadêmica em Psicomotricidade.

\subsubsection{Esquema corporal}

Houve concordância entre as entrevistadas em relação ao modo como trabalham o esquema corporal. A maioria afirmou utilizar músicas que possuem comandos relacionados às partes do corpo como ilustrado nos discursos da Tabela 2.

Tabela 2 - Recurso utilizado para o trabalho com esquema corporal

\begin{tabular}{|c|c|}
\hline P1 & $\begin{array}{l}\text { re vou lá para fora com eles, às vezes uso a sala mesmo, } \\
\text { nbaixo. }\end{array}$ \\
\hline $\mathbf{P}$ & $\begin{array}{l}\text { abalho. Principalmente com música, porque como eles são peq } \\
\text { aços. Outras músicas falam da mão, do lado direito lado esqu } \\
\text { corpo que ai vai buscando. Principalmente com músicas. }\end{array}$ \\
\hline P3 & Kuxa "cabeça, joelho, ombro e pé". Ai a \\
\hline $\mathbf{P}$ & $\begin{array}{l}\text { Isso é sempre, através da música, de expressão, a gente tá sempre trabalhando a expressão } \\
\text { corporal, por exemplo, levanta a mão direita, de tocar as partes do corpo enquanto vai } \\
\text { cantando. }\end{array}$ \\
\hline & $\begin{array}{l}\text { Musiquinhas é o } \\
\text { das principais "o }\end{array}$ \\
\hline
\end{tabular}

A percepção do próprio corpo (esquema corporal) pode ser definida como uma organização psicomotora global, compreendendo todos os níveis motores, tônicos, perceptivos sensoriais e expressivos, estando o aspecto afetivo constantemente investido (Barreto, 2000). Esta função psicomotora é essencial também para a construção da 
personalidade da criança. O esquema corporal fundamenta-se principalmente em órgãos relacionados com a postura e as posições do corpo. As experiências com o próprio corpo por meio de músicas, brincadeiras, como engatinhar, andar, fazer movimentos livres são fundamentais para o desenvolvimento.

Entretanto, o corpo não deve ser compreendido como apenas uma estrutura biológica, mas também como um meio de expressar emoções e estados interiores. É importante que o educador auxilie seus alunos, no sentido de permitir que eles centrem, em si mesmos, a atenção, facilitando o processo de interiorização do corpo, que é fundamental para que a criança tome consciência de seu esquema corporal (Oliveira, 2012).

Nesta direção, é possível perceber que o trabalho realizado pelas professoras (P1, P2, P3, P5 e P7) corresponde a essa busca pela descoberta do corpo, sendo realizadas atividades que proporcionam 0 conhecimento das partes do corpo. A professora P8 deu um exemplo diferente das demais, sobre como realiza o trabalho de esquema corporal: Os próprios livros já chegam com atividades que trabalham o esquema corporal, uma vez eu fiz uma atividade que eles deitavam no chão, aí eu colocava o giz e eles desenhavam o formato do corpo do colega, depois ele deitava e o coleguinha também desenhava o formato do corpo, foi bem legal que eles já conseguiram ter uma noção do corpo.

Neste exemplo, é interessante notar que a professora faz com que seus alunos percebam seu próprio corpo, ao mesmo tempo em que percebem os corpos de seus amiguinhos; ao desenhar o corpo do outro, a criança que é desenhada, tem a experiência de perceber o seu próprio corpo no desenho. Portanto, esta é mais uma atividade rica que pode ser desenvolvida pelos professores da Educação Infantil e que, inclusive, já se encontram em livros destinados a esta etapa da escolaridade. Apenas P6 e P4 relataram não realizaram nenhuma atividade para trabalhar o esquema corporal.

\subsubsection{Orientação espacial}

Das quatro professoras, que afirmaram trabalhar esta função psicomotora, duas se referiram à aprendizagem das noções espaciais: em cima, embaixo, dentro e fora. As professoras P5, P2, P6 e P8 afiançaram que desenvolvem atividades visando à orientação espacial, enquanto as demais não souberam responder esta pergunta. A literatura preconiza que primeiro a criança percebe a posição do seu próprio corpo no espaço, para depois perceber a posição dos objetos em relação a ela própria, aprendendo, por fim, a perceber a posição dos objetos entre si (Oliveira, 2012).

Porém, para que a criança consiga perceber os objetos no espaço, precisa primeiramente ter uma boa imagem corporal, pois esta é usada 
como ponto de referência. A criança somente conseguirá apreender as noções espaciais, por meio da movimentação, e da exploração intensa do ambiente. Aos poucos a criança vai aprendendo as noções de situações (dentro, fora, no alto, abaixo); de tamanho (grosso, fino, grande, médio); de posição (em pé, deitado, sentado); movimentos (levantar, baixar, subir, descer); de formas (cheio, vazio, pouco, muito); de qualidade (cheio, vazio, pouco, muito). Assim, pode-se perceber que a orientação espacial vai muito além de conceitos como dentro, fora, em cima, embaixo, possibilitando à criança uma maneira de se relacionar com o mundo, de maneira complexa.

As professoras P6 e P8, que afirmaram desenvolver atividades que trabalham a orientação espacial, ofereceram exemplos interessantes. Há demonstração de compreensão sobre a função de orientação espacial: “[...] na educação infantil a gente trabalha com brincadeiras e com jogos e faz muitas brincadeiras na quadra... o carrinho de mão, que vai exigir força, equilíbrio, concentração e também espaço... eles amam fazer... uma criança coloca a mão no chão e outra segura nas pernas, aí vai correndo até no ponto, e depois volta. é engraçado que eles pensam que não, mas já tão entrando no espaço do outro... por aí a gente percebe que ta desenvolvendo a orientação espacial" (P6).

Pode-se perceber pelo relato de P6 que, para se realizar atividades que trabalhem a orientação espacial, é necessária a utilização da quadra, um local com mais espaço do que a sala de aula. A atividade desenvolvida por ela abrange diversas outras funções psicomotoras como equilíbrio, concentração e, claro, o espaço, ou seja, a criança é estimulada a movimenta-se e relacionar-se com o espaço a sua volta, tendo inclusive a ajuda de outro coleguinha para conseguir se locomover em um determinado ambiente.

A professora P8 chamou a atenção pelo fato de relacionar a questão espacial com o ato de escrever, sendo realizado este treino por meio da escrita do nome, observando a maneira como ele é colocado em um determinado espaço. Ou seja, por meio da escrita é possível perceber de que maneira a orientação espacial se encontra desenvolvida na criança, dando pistas para o educador sobre o desenvolvimento psicomotor de seus alunos: "Você pode fazer várias atividades... nós colocamos bolas coloridas no chão, dependendo da cor que eu dizia, eles não podiam sair do lugar, ou não... por exemplo, vamos pular para esse círculo amarelo... daí já tá trabalhando o espaço com eles. E também o nome, porque é a partir daí que a gente começa a trabalhar o espaço na escrita... se o nome é grande ou pequeno, como colocar na linha, essas coisas".

A criança explora o espaço para perceber suas dimensões, formas, limites, layout, obstáculos e aprende a adaptar o seu comportamento, dependendo das exigências do ambiente. Ser coordenada e executar com rapidez e eficiência os movimentos intencionais para resolver tarefas concretas são quesitos vitais para o desenvolvimento de 
atividades na vida adulta. Então, é fundamental salientar a importância do papel do professor ao mediar noções de localização, movimento, deslocamento no ambiente, percepção das coisas do mundo/espaço próximo e distante, bem como a possibilidade de construção de um mundo real ou imaginário (Bouchard, 2008). E essa compreensão das relações espaciais, não se baseia unicamente no raciocínio de situações espaciais precisas, mas deve levar a criança a perceber a relação entre os vários elementos que deve primeiro analisar, a fim de imaginar combinações ou itens em falta.

\subsubsection{Orientação temporal}

A orientação temporal está intimamente relacionada com a orientação espacial, pois quando o sujeito se desloca em um determinado espaço, ele o faz em um dado tempo (Oliveira, 2012). Porém, a percepção temporal se dá através de ritmos, conceitos de duração, intervalos, continuidade, simultaneidade e sucessão.

Outro elemento, considerado importante para a aquisição dessa função psicomotora, é o som; por meio dele a criança pode experimentar situações que envolvem duração, alternância e simultaneidade. As percepções do "depois", "antes" e "agora" são extremamente importantes para língua falada e escrita; logo, é importante que, tanto em casa quanto na escola, as crianças possam vivenciar tais percepções, já que são conceitos abstratos, de difícil compreensão, necessitando de treino diário.

Algumas dimensões do tempo que a criança necessita adquirir para poder ter uma melhor compreensão do presente, passado e futuro, de acordo com Frank, Land, Popp e Schack (2014) são: sequência de ações (habilidade para organizar fatos); noções básicas de temporalidade (agora, ontem, amanhã, etc.); velocidade (movimentos lentos e acelerados); duração (tempo gasto para realizar uma determinada tarefa); ritmo (lento, acelerado, cadência). Então, pode-se perceber no discurso de P2, P3, P4, P5 e P7 que elas realizam sim um trabalho de orientação temporal, abrangendo principalmente atividades que proporcionam a aprendizagem de horas, datas, e questões climáticas.

P2 se referiu à orientação temporal como sendo desenvolvida por meio da aprendizagem das horas, P3 afiançou que ensina para seus alunos os aspectos climáticos e P5 e P4 deram mais ênfase na aprendizagem dos dias da semana, quando faz um treino do calendário (Tabela 3 ). P7 afirmou trabalhar com as crianças tanto as horas quanto os aspectos climáticos. Duas professoras não souberam responder sobre este tema. 
Tabela 3 - Conteúdos trabalhados para promover orientação temporal

\begin{tabular}{|l|l|}
\hline P2 & Também... o relógio, a hora da merenda, a hora de entrar, de sair, de descansar. \\
\hline P3 & $\begin{array}{l}\text { Sim, em relação ao tempo né? A gente trabalha muito a questão de como ver o céu, ai por } \\
\text { exemplo, tá ensolarado, tá nublado, tá chuvoso. }\end{array}$ \\
\hline P4 & $\begin{array}{l}\text { Eu procuro trabalhar todos os dias com eles a questão do tempo, a semana, dias da semana, o } \\
\text { mês, o ano. }\end{array}$ \\
\hline P5 & Também é trabalhado, os dias da semana, todo dia é trabalhado no calendário. \\
\hline P7 & $\begin{array}{l}\ldots \text { a gente tem um cartàozinho que a gente coloca na sala com os horários, a rotina deles, e } \\
\text { também sobre o tempo, quando tá chuvoso, quando tá mublado... a hora de ir embora... }\end{array}$ \\
\hline
\end{tabular}

Nesta subcategoria os procedimentos englobam conteúdos que permitem oferecer orientação temporal em várias modalidades. 0 calendário e o relógio, atrelados à rotina diária, sãos recursos relevantes; as condições climáticas são realidades e vivências aproveitadas para promover esta instância da psicomotricidade. Porém, mais uma vez, os déficits na formação acadêmica se sobressaem, quando as profissionais não souberam responder sobre a orientação temporal.

É imprescindível destacar que o professor de Educação Infantil tem um papel importante na percepção e ajuste de suas atividades para diferentes componentes de tempo, tais como ordem e sucessão, duração, intervalo, velocidade, bem como na localização e navegação no tempo tomado como sucessão linear irreversível e, também, na organização no tempo ao combinar diversos elementos, a fim de atingir objetivos relacionados à organização temporal (Rigal, 2009).

\subsubsection{Coordenação motora ampla}

A coordenação motora ampla, também denominada de coordenação global, concerne a atividades dos grandes músculos, dependendo da capacidade postural do sujeito (Oliveira, 2012). Por meio do desenvolvimento do equilíbrio, a criança vai se tornando cada vez mais capaz de realizar movimentos coordenados. Com este tipo de coordenação, o sujeito também será capaz de dissociar os movimentos, no qual cada membro é capaz de realizar um movimento ao mesmo tempo. Muitas crianças já chegam à educação infantil apresentando certo domínio da coordenação motora ampla, porém outras apresentam mais dificuldades, cabendo ao professor avaliar as aquisições anteriores, devendo observar a relação entre postura e controle do corpo, corrigindo, caso necessário.

Neste quesito, a resposta que mais se encaixou com o que se encontra na literatura sobre psicomotricidade foi da P7. Ela traz o jogar bola, o uso do bambolê, pular corda e amarelinha, como exemplos de atividades que ajudam no desenvolvimento da coordenação motora ampla: "[...] a coordenação para jogar bola é legal, usar o bambolê também... quando roda num braço, roda no outro... pular corda 
também é muito legal, deixa eu ver outra, amarelinha, porque eles dão um pulo com o pé e depois com os dois".

Para P4 a falta de espaço não é algo que impede o desenvolvimento de certas atividades, pois assegura que ela afasta a mesa, todos sentam no chão e realizam as atividades de coordenação motora ampla, que exige um local maior para poder ser trabalhada: “[...]o espaço da sala de aula dá para trabalhar... depende do professor... nós afastamos todas as mesas e cadeiras e vamos trabalhar a coordenação, senta no chão, dá a mão um pro outro, toda uma atividade, andar em linha reta, com um pé na frente do outro [...]". O exemplo dado por P4 envolve um trabalho voltado para o equilíbrio. Porém, todos os grandes músculos são utilizados e o equilíbrio está estreitamente relacionado com a coordenação motora ampla.

Algumas professoras confundiram a função psicomotora de coordenação motora ampla com coordenação motora fina: "Tem atividades de montagens, pecinhas, tem os encaixes de canudinho, tem pontilhados... massinha de modelar, tesoura, as bolinhas de papel" (P1). É possível que a professora tenha se confundido e acabou por dar exemplos claramente voltados para o trabalho da coordenação motora fina. As outras professoras não souberam dar exemplos de atividades que trabalhem a coordenação motora ampla.

Equilíbrio é uma habilidade importante para o desenvolvimento motor bruto da criança, pela sua importância para desenvolver ganho de confiança e habilidades nos movimentos físicos e de coordenação (Oliveira, 2012). Desde cedo, a criança aprende a se equilibrar para engatinhar; crianças da Educação Infantil aprendem a saltar com os dois pés, chutar uma bola, saltar e vestir-se, além de ganhar habilidades em esportes e jogos.

\subsubsection{Coordenação motora fina}

A coordenação motora fina constitui um aspecto particular da coordenação motora ampla, sendo compreendida como a capacidade do sujeito de preensão por meio das mãos, conhecendo cada vez mais os objetos que fazem parte de seu meio ambiente (Magill, 2011). A escrita começa a ser possível, a partir do momento em que o sujeito passa a ter maior destreza do seu braço em relação ao ombro, conseguindo chegar cada vez mais perto do controle da preensão sobre os dedos (Kambas et al., 2010). Experiências de lançar e pegar são importantes para a escrita, assim como o desenho e o grafismo.

Todas as professoras deram exemplos de atividades que trabalham a coordenação motora fina, sendo esta a categoria em que houve maior número de respostas que concordaram e que foram ao encontro do que literatura aborda sobre Psicomotricidade. Os trabalhos manuais prevaleceram - desenhos, recortes, pinturas, uso de massinha de modelar: "Lápis, pintura, a pintura dentro do desenho, no limite onde 
estão as linhas, massinha de modelar [...]" (P7), bem como pontilhados, figuras geométricas, aprendizagem da escrita, etc., estando sempre presente a preensão do objeto por meio das mãos: “O livro da escola, que é um livro de caligrafia, trabalha a questão do pontilhado, linhas curvas, linhas retas, círculos, entra também as formas geométricas..." (P4). O uso de objetos variados, incluindo a tesoura, também foram mencionados: "[...] com crepom, com colagem, com palito de picolé, palito de fósforo, com papelzinho, folhas de revista, tudo eles recortam à mão". (P2)

\subsubsection{Equilíbrio}

Para que exista coordenação, deve existir equilíbrio, esta função psicomotora básica é fundamental para a sustentação e manutenção do corpo humano (Alves, 2008). P7, P3, P8 e P1 fizeram menção ao uso da amarelinha, do pular a corda e andar sobre uma linha reta, como meios de trabalhar o equilíbrio nas crianças (Tabela 4). Nessa categoria, houve concordância entre as respostas das entrevistadas, uma vez que o trabalho do equilíbrio está intimamente ligado à coordenação motora ampla, logo são realizadas atividades que exigem um movimento do corpo todo. E o movimento incentiva um relacionamento saudável com o próprio corpo, além de desenvolver uma aprendizagem prazerosa (Levin, 2015).

Tabela 4-Atividades promotoras de movimento

\begin{tabular}{|l|l|}
\hline P1 & Através da música. Fica de um pé só, quem consegue equilibrar uma coisinha da colher... \\
\hline P3 & $\begin{array}{l}\text { Por exemplo na corda, a criança tem que se equilibrar em cima da corda, coloca a corda no } \\
\text { chão e vai passar por cima da corda, sem ter que cair. }\end{array}$ \\
\hline P7 & $\begin{array}{l}\text { Amarelinha trabalha o equilibrio, pula corda também trabalha o equilibrio, a gente canta } \\
\text { musiquinhas também que é pular em um pé só... a gente brinca imitando os animaizinhos, o } \\
\text { movimento que eles fazem. }\end{array}$ \\
\hline P8 & $\begin{array}{l}\text { Eles trabalham nas escolas muito na parte de recreação, porque se eles pulam uma corda, eles } \\
\text { já estão trabalhando o equilibrio... pega-pega, manja trepa. }\end{array}$ \\
\hline
\end{tabular}

Quanto a outras atividades psicomotoras desenvolvidas na Educação Infantil, todas as entrevistadas responderam que não realizam outras atividades de cunho psicomotor. Ou seja, outras funções psicomotoras como imagem corporal, coordenação visomotora, coordenação audiomotora não foram mencionadas. É imperativo reconhecer que o controle postural é o ponto de partida das habilidades motoras voluntárias. Este controle é importante porque precede o desempenho de qualquer tarefa motora. Se uma criança não tem um bom controle postural, não pode manter posição correta. Esta é a razão principal pela qual equilíbrio é um componente fundamental ar ser estimulado através de atividades motoras (Levin, 2015). Na verdade, a aquisição das habilidades de equilíbrio vai ajudar a desenvolver a coordenação 
motora grossa, coordenação motora fina, e as habilidades de autoatendimento.

\section{ATI VI DADES PSI COMOTORAS: ASPECTOS FACI LITADORES}

Foi possível perceber quais são os aspectos considerados facilitadores para a realização das atividades psicomotoras. P1 e P5 relataram que o momento em que ocorre a educação física é uma possibilidade para desenvolver a psicomotricidade. P3, P4 e P7 relataram que as instituições nas quais trabalham colaboram muito para 0 desenvolvimento de do trabalho em Psicomotricidade, fornecendo materiais e espaços adequados; uma professora relatou que o livro didático tem ajudado bastante, porque ele está repleto de atividades que trabalham o desenvolvimento psicomotor.

Entretanto, além do ambiente e dos recursos materiais, ela afiançou que a Psicomotricidade só não é trabalhada se o profissional não tiver comprometimento: “[...] você só não trabalha a psicomotricidade com as crianças que é fundamental para o desenvolvimento delas, se você não quer, porque tudo, tudo o que você vai fazer tá ligado a psicomotricidade.... mas o professor precisa ser comprometido, ter vontade [...]"(P6). Nesta perspectiva, também depende do nível de compreensão das partes interessadas em relação à promoção de exercícios relativos à psicomotricidade, dos recursos materiais disponíveis em cada unidade escolar e, finalmente, do nível de motivação dos adultos - professor, escola - para seguir se aperfeiçoando no assunto (Riethmuller et al., 2009).

Para facilitar o trabalho dos professores, é necessário que se ofereçam oficinas de formação para eles compartilharem seus conhecimentos com seus colegas e que, nestas oficinas, tenham convidados especialistas em Psicomotricidade e em Educação Física. Ainda, é necessário que haja investimento em materiais e equipamentos, bem como espaço no físico nas unidades escolares, para que as atividades motoras sejam desenvolvidas a contento (Tucker, Zandvoort, Burke \& Irwin, 2011; Trost, Ward, \& Senso, 2010).

\section{ATI VI DADES PSI COMOTORAS - ASPECTOS DI FI CULTADORES}

Nesta dimensão, é interessante notar que P1 e P5 afirmaram que a falta de materiais é algo que dificulta o desenvolvimento das atividades psicomotoras; uma delas afirmou que o espaço não adequado é outro dificultador: "O grande problema é o material que a gente não dispõe... às vezes a gente tem que tirar do próprio bolso, tem que fazer milagre, para conseguir realizar algumas atividades" (P1). 
P4 afirma que a falta de outros especialistas nas escolas, que saibam trabalhar com crianças, que apresentam falhas no desenvolvimento psicomotor, pode ser considerada como um aspecto dificultador, pois estes profissionais iriam auxiliar em relação ao modo de se trabalhar com tais crianças. P6 acredita que a indisciplina de alguns alunos atrapalha o andamento de algumas atividades e P8 acredita que em algumas escolas existam profissionais não aptos para desenvolverem certas atividades, prejudicando o desenvolvimento de seus alunos. P7 ainda não encontrou nenhuma dificuldade.

É possível perceber que a realidade de algumas escolas não se harmoniza com os objetivos preconizados pelas Diretrizes Curriculares Nacionais para Educação Infantil, que asseguram que estas instituições devem prover condições materiais, tempo e espaço para o trabalho coletivo (Ministério da Educação, 2010). Também, está devidamente documentado que informações bem estruturadas com exemplos de jogo e atividades não seriam usadas pela maioria dos professores (Martin \& Hands, 2003; Willrich, Azevedo, \& Fernandes, 2009). E esta resistência à promoção e prática da Psicomotricidade deveria ser vista em uma reflexão sobre o papel dos educadores em cuidados infantis, tanto nas disciplinas dos cursos universitários quanto na formação continuada.

\section{CONSI DERAÇÕES FI NAIS}

Este estudo constatou que as professoras concebem o campo da Psicomotricidade interligado à educação infantil. Mas, de que maneira é feita esta ligação? As repostas variaram, destacando-se as falas de duas professoras que afirmaram ser o lúdico o meio mais adequado para estabelecer tal contato, indo ao encontro da literatura.

Mas, observou-se que as participantes não possuíam um conhecimento aprofundado sobre a temática da psicomotricidade e não realizavam um trabalho específico de educação psicomotora. Algumas funções como lateralidade, esquema corporal, coordenação motora ampla, coordenação motora fina, orientação temporal, orientação espacial, são trabalhadas, mas, nem sempre da maneira mais adequada, uma vez que alguns equívocos conceituais, quanto às funções citadas anteriormente, foram percebidos.

Pôde-se também constatar que a temática relacionada à psicomotricidade, estudada durante a Graduação, havia sido parcialmente esquecida, o que talvez explique a dificuldade em responder algumas perguntas que estavam presentes no roteiro da entrevista. Isso prejudica o andamento das atividades psicomotoras na escola, uma vez que as educadoras deveriam ter um bom domínio sobre o campo da Psicomotricidade, para que pudessem realizar um trabalho consciente e adequado para o desenvolvimento de seus 
alunos. Porém, a maioria das professoras apresentou pouco tempo de trabalho, após a formação em pedagogia, estando, ainda, a investir em especializações e cursos de capacitação, é provável que futuramente venham a ter um mais contato e mais conhecimento sobre esta temática.

É importante lembrar que as Diretrizes Curriculares Nacionais para a Educação Infantil têm, como um de seus objetivos, o respeito pela indivisibilidade entre as dimensões expressivo-motora, afetiva, cognitiva, linguística, ética, estética e sociocultural das crianças, demonstrando que o trabalho a ser realizado requer um constante aprimoramento e renovação de conhecimentos, uma vez que a educação infantil é responsável por deixar grandes marcas no desenvolvimento global da criança, atuando de maneira preventiva.

O campo da Psicomotricidade deveria ser amplamente difundido, ganhando respeito e atenção, principalmente dos gestores da Educação Infantil, para que possa realmente ser posta em prática junto à educação formal, sendo trabalhada de maneira consciente e comprometida não apenas pelos docentes, mas por toda a instituição. Vale salientar que o conhecimento nesta área implicará grandemente em sua instrumentalização, que se mostra necessária e é o diferencial de um profissional capacitado. A Psicomotricidade é reconhecida como uma ciência que muito tem a contribuir para o desenvolvimento humano, em todas as suas etapas, da infância à velhice, e em toda sua complexidade, pois afeto, cognição e movimento são inseparáveis e fazem parte da condição humana.

\section{Referências}

Alves, F. (2008). Psicomotricidade: Corpo, ação e emoção. Rio de Janeiro: Walk.

Araújo, D. S. de. (2012). Formação e prática de professores de educação infantil sob o olhar da psicomotricidade (Monografia de Graduação em Pedagogia). Universidade Estadual da Paraíba, Campina Grande.

Bardin, L. (2010). Análise de Conteúdo (4. ed.). Lisboa: LDA.

Barreto, S. J. (2000). Psicomotricidade: Educação e reeducação. Blumenau: Acadêmica.

Barreto, S. J., Zimmermann, C., Cartier, E., \& Nunes, C. (2012). A importância da psicomotricidade para crianças de 0 a 3 anos. EFDeportes Revista Digital, 15(166). Retirado de http://www. efdeportes.com/efd166/a-importancia-da-psicomotr icidade-para-criancas. htm

Bouchard, C. (2008). Le développement global de l'enfant de 0 à 5 ans en contexte éducatifs. Quebec: Les Presses de I'Université du Québec. 
Fonseca, V. (2012). Psychomotor Observation Manual: psiconeurológica meaning of psychomotor factors (2. ed.). Rio de Janeiro: Walk.

Fonseca, V. (2005). Desenvolvimento psicomotor e aprendizagem. Lisboa: Âncora.

Frank, C., Land, W. M., Popp, C., \& Schack, T. (2014). Mental Representation and Mental Practice: Experimental Investigation on the Functional Links between Motor Memory and Motor I magery. PLoS ONE (Bethesda), 9(4), 17-35.

Hensius, A. (2010). Fundamentos Psicológicos da Psicomotricidade na Área da Saúde. In C. A. Ferreira, \& A. N. Hensius, A. (Org.), Psicomotricidade na Saúde (pp. 47-64). Rio de Janeiro: Walk Editora.

Kambas, A., Fatouros, Y., Christoforidis, C., Venetsanou, F., Giannakidou, D., \& Aggeloussis, N. (2010). The effects of Psychomotor Intervention, on Visual-Motor Control as a Graphomotor aspect in preschool age. European Psychomotricity Journal (Greece), 3(1), 54-61.

Lapierre, A. (1986). A educação psicomotora na escola maternal. São Paulo: Manole.

Le Boulch, T. (1982). O desenvolvimento psicomotor do nascimento até 6 anos. Porto Alegre: Artes Médicas.

Levin, Esteban. (2015). The body helps the student to learn. Interview of Paola Gentile. New School.

Macri, A. C. (2014). The role of the exercises in the improvement of the psychomotricity components in the development of the pupils. Sport \& Society / Sport si Societate, 14, 155-162.

Magill, R. A. (2011). Motor learning and control: Concepts and applications. McGraw-Hill, New York: NY.

Martin, M., \& Hands, B. P. (2003). Implementing a Fundamental Movement Skill program in an early childhood setting: The teacher's perspectives. Australian Journal of Early Childhood, 28(4), 47-52.

Ministério da Educação. Secretária de Educação Básica. (2010). Diretrizes curriculares nacionais para a educação infantil. Brasília: MEC.

Oliveira, G. C. (2012). Psicomotricidade: educação e reeducação num enfoque psicopedagógico. Petrópolis: Vozes.

Pieg, L., \& Vayer, P. (1971). Education psychomotrice et arrie ration mentale. Paris: DOIN.

Riethmuller, A. M., R. A. Jones, R. A., \& Okely, A. D. (2009). Efficacy of interventions to improve motor development in young children: a systematic review. Pediatrics, 124(4), 782-792.

Rigal, R. (2009). L'éducation motrice et l'éducation psychomotrice au préscolaire et au primaire. Quebec: Les Presses de l'Université du Québec. 
Sayão, D. T. (2002). Corpo e movimento: notas para problematizar algumas questões relacionadas à Educação I nfantil e à Educação Física. Revista Brasileira Ciência do Esporte, 23, 2, 55-67.

Sugrañés, E., \& Ángel, M. A. (2007). La educación psicomotriz (3-8 años). Cuerpo, movimiento, percepción, actividad: Una propuesta teórico-práctica. Barcelona: GRAÓ.

Trost, S. G., Ward, D. S., \& Senso, M. (2010). Effects of child care policy and environment on physical activity. Medicine et Science in Sports et Exercise, 42(3), 520.

Tucker, P., Zandvoort, M. M., Burke, S. M., \& Irwin, J. D. (2011). Physical activity at daycare: Childcare providers' perspectives for improvements. Journal of Early Childhood Research, 9(3), 207-219.

Wallon, H. (2007). A evolução psicológica da criança. São Paulo: Martins Fontes.

Wauters-Krings, F. (2009). Psychomotricité à l'école maternelle. Les situations motrices au service du développement de l'enfant. Bruxelles: De Boeck.

Willrich, A., Azevedo, C. F., \& Fernandes, J. O. F. (2009). Desenvolvimento motor na infância: influência dos fatores de risco e programas de intervenção. Revista de Neurociência, 7, 51-56.

\section{Endereço para correspondência I donézia Collodel Benetti}

Universidade Federal de Santa Catarina - UFSC

Programa de Pós-Graduação em Saúde Coletiva

Campus Reitor J oão David Ferreira Lima

Rua Delfino Conti, s/n, bloco H, Trindade, CEP 88040-900, Florianópolis - SC, Brasil Endereço eletrônico: idonezia@hotmail.com

\section{Paulo Henrique Pinheiro de Barros}

Universidade Federal de Roraima - UFRR

Instituto de Gestalt-terapia de Roraima - Ampliando Fronteiras

Rua Chico Lira, 153, São Francisco, CEP 69305-093, Boa Vista - RR, Brasil

Endereço eletrônico: paulobarross@outlook.com

\section{Fernanda Ax Wilhelm}

Universidade Federal de Roraima - UFRR

Centro de Educação - CEDUC

Av. Capitão Ene Garcez, 2413, bl I sl 4, Aeroporto, CEP 69310-003, Boa Vista - RR, Brasil

Endereço eletrônico: fernanda.ax@ufrr.br

Ana Paula da Rosa Deon

Universidade Federal de Roraima - UFRR

Centro de Educação - CEDUC

Av. Capitão Ene Garcez, 2413, bl I sl 4, Aeroporto, CEP 69310-003, Boa Vista - RR, Brasil

Endereço eletrônico: ana.deon@ufrr.br 
Idonézia Collodel Benetti, Paulo Henrique Pinheiro de Barros, Fernanda Ax Wilhelm, Ana Paula da Rosa Deon, João Paulo Roberti Junior

\section{J oão Paulo Roberti J unior}

Universidade Federal de Santa Catarina - UFSC

Programa de Pós-Graduação em Saúde Coletiva

Campus Reitor J oão David Ferreira Lima

Rua Delfino Conti, s/n, bloco H, Trindade, CEP 88040-900, Florianópolis - SC, Brasil

Endereço eletrônico: joaoroberti@gmail.com

Recebido em: 13/02/2015

Reformulado em: 22/08/2017

Aceito em: 26/08/2017

\section{Notas}

* Mestre em Psicologia e Doutoranda em Saúde Coletiva na Universidade Federal de Santa Catarina.

** Psicólogo Clínico. Graduação em Psicologia pela Universidade Federal de Roraima. *** Doutora em Psicologia na Universidade Federal de Santa Catarina. Professora do Curso de Psicologia da Universidade Federal de Roraima.

**** Mestre em Administração na FURB. Professora do Curso de Psicologia da Universidade Federal de Roraima.

***** Mestre em Antropologia Social e Doutorando em Psicologia na Universidade Federal de Santa Catarina.

O presente trabalho foi realizado com apoio da Coordenação de Aperfeiçoamento de Pessoal de Nível Superior - Brasil (CAPES) - Código de Financiamento 001.

Este artigo de revista Estudos e Pesquisas em Psicologia é licenciado sob uma Licença Creative Commons Atribuição-Não Comercial 3.0 Não Adaptada. 